\title{
Do surgimento das favelas cariocas a UPP: políticas públicas de segurança, segregação, controle e a formação de contra movimentos locais
}

From the emergence of the Rio de Janeiro slums to the UPP: public security policies, segregation, control and the formation of local counter movements

\author{
Lorene Maia ${ }^{\dagger *}$, Carolina Mara Teixeira ${ }^{\dagger}$, Fausi Kalaoum \\ Como citar esse artigo. Maia, L.;

\section{Resumo}

Teixeira, C.M.; Kalaoum, F. Do

surgimento das favelas cariocas a UPP: políticas públicas de segurança, segregação, controle e a formação de contra movimentos locais. Revista Mosaico, v.11, n.2, p. 11 - 18, 2020.

O presente artigo tem por objetivo demonstrar como a ação do Estado, enquanto formulador e implementador das políticas públicas na cidade do Rio de Janeiro e promotor do planejamento urbano propiciaram o surgimento e a expansão das favelas cariocas e de que maneira essas políticas, corroboraram o processo de segregação e controle nas e das favelas. A partir dessa perspectiva, pretende-se analisar os efeitos dessas políticas públicas específicas que incidiram nesses espaços, discutindo o real papel das UPP nas favelas enquanto política pública de segurança ou de ordenamento social. Dessa forma, objetiva-se promover, por meio de revisão bibliográfica, uma análise acerca da formação e desenvolvimento das favelas, buscando paralelamente, entender como as políticas públicas implementadas, norteadoras do planejamento urbano da cidade, consolidaram esse contexto social excludente que promove a retórica do sistema capitalista de apropriação e de uma globalização com efeitos perversos, mas também propicia condições adversas que fazem emergir contra movimentos articulados em redes, que objetivam resistir às investidas e ao controle do poder hegemônico.

Nota da Editora. Os artigos publicados na Revista Mosaico são de responsabilidade de seus autores. As informações neles contidas, bem como as opiniões emitidas, não representam pontos de vista da Universidade de Vassouras ou de suas Revistas.

Palavras-chave: Favela; Planejamento Urbano; Políticas-Públicas; Redes; UPP.

\begin{abstract}
This article aims to demonstrate how the State action, as formulator and implementer of public policies in the city of Rio de Janeiro and promoter of urban planning, led to the emergence and expansion of Rio's favelas and how these policies corroborated the segregation and control process in and from favelas. From this perspective, we intend to analyze the effects of these specific public policies that affected these spaces, discussing the real role of the UPP in the favelas as a public security or social policy. Thus, the objective is to promote, through literature review, an analysis about the formation and development of the favelas, seeking in parallel to understand how the implemented public policies, guiding the urban planning of the city, consolidated this exclusionary social context that promotes rhetoric of the capitalist system of appropriation and of a globalization with perverse effects, but also provides adverse conditions that give rise to networked counter movements that aim to resist the onslaughts and control of hegemonic power.

Keywords: Favela, Urban Planning, Policies, Networks, UPP.
\end{abstract}

\section{Introdução}

As favelas, especialmente as alocadas nas grandes urbes, são vistas enquanto um território peculiar devido aos aspectos sociais, políticos, econômicos e culturais que contornam o seu processo de formação em um território tão plural quanto o brasileiro. Especificamente àquelas ligadas ao município do Rio de Janeiro que se apresentam cada vez mais enquanto territórios repletos de estórias, personagens, memórias, cenários urbanos e culturas específicas de uma identidade carioca, capaz de propor uma nova perspectiva da "cidade maravilhosa" (FGV, 2013).

De acordo com Villaça (2001), historicamente é possível entender a formação das favelas enquanto estigmas de um crescimento desordenado, que tem como uma de suas características mais marcantes a proposição de segregação espacial de bairros residenciais, conforme suas distintas classes sociais, criando-se, a partir desse cenário, verdadeiros sítios sociais.

Ao tentar esclarecer a segregação territorial nas cidades, Campos (2009) analisou que os primeiros moradores das distintas classes sociais nas cidades representavam na sociedade republicana o conflito de classes: os mais pobres, ao ocuparem as favelas as fizeram tal como os quilombos, na sociedade escravocrata. Nesse sentido, os que viviam nas favelas, tanto quanto nos quilombos, integravam a mesma classe "perigosa". Sendo os quilombolas uma forma representativa do passado: a ameaça ao Império; e os favelados considerados os marginalizados e indesejados na sociedade na República. Dessa forma, é possível observar que, desde sua gênese, a cidade foi local de 
produção de expectativas e demandas sob a perspectiva - contra o outro e não com o outro.

Campos (2005) indicou que assim como os quilombos, as favelas sempre foram motivos de desinquietação das classes dominantes, por serem habitadas por pessoas consideradas da classe perigosa, por representar o diferente, o outro em relação à ocupação do espaço urbano, "a favela surge no cenário urbano do Rio de Janeiro, sem estar contextualizada em um processo social, mas como resultante de fatos espaciais e temporalmente delimitados." (CAMPOS, 2005, p. 63).

Desta forma, as favelas no Rio de Janeiro são originadas desse processo de segregação, que resultou em políticas sanitaristas no centro da cidade que derrubaram os Cortiços como forma de embelezá-la e torná-la mais atraente e "européia". Sob essa perspectiva, as diferenças sócias espaciais geradas podem ser encaradas como a mais profunda consequência do modelo capitalista de produção do espaço para ser vendável a um estilo de vida hegemônico. Pode-se dizer então que ao longo das últimas décadas de expansão da economia, as metrópoles brasileiras sempre estiveram e ainda hoje estão reorganizando seus espaços em um contexto de concorrência global, almejando atividades econômicas e serviços avançados para manterem-se dentro do sistema político-econômico mundial (LANÇA; MAIA; SANTANA, 2015).

Paralelamentea essa "organizaçãodasmetrópoles" existe nas favelas, desde sua formação, uma capacidade de mobilização, luta e articulação própria da população local, um movimento de resistência ativa a que Santos (2007) se referiu. Foi dessa forma que, historicamente, ainda que sob perseguição e miséria, a população segregada não deixou a cidade, ocupando os morros e as áreas mais distantes do centro, fazendo prevalecer na cidade à cultura popular e a diversidade social e racial, características provenientes da formação do território brasileiro.

É a partir desse ponto, que a formação das favelas da cidade carioca, no início do século XX, passa a estar associada à imagem das mazelas do homem: espaço da pobreza e da miséria, reduto dos pobres e, portanto, passa a ser encarada enquanto um problema social (VALLADARES, 2000).

Justamente por conta de sua mobilização e resistência e por se tratar de um "problema social" é que no decorrer dos anos, políticas públicas foram implementadas na cidade do Rio de Janeiro com a finalidade de eliminar o crescimento das favelas, coibir o surgimento de novas e conter sua articulação política. Contudo, mais reações populares de moradores, de estudantes e de intelectuais que lutavam por um processo de urbanização democrático do espaço urbano, foram ocorrendo, como indicam Barreira e Botelho (2008) fazendo, desses espaços, locais ainda mais fortes e focos de resistência.

Assim, definidas pela ausência de recursos e pela paisagem, as favelas foram originadas a partir de um histórico de ocupação segregacionista onde se reproduzem ações ou "não" ações das instituições do mundo social, das políticas públicas, dos investimentos privados e de organizações sociais. As favelas são/foram por muito tempo alvos de iniciativas fragmentadas que não priorizaram a diversidade e nem a intensa vida social local, subjulgadas por ações assistencialistas que segregaram e ordenaram a população favelada, promovendo a ideia de "Cidade Partida". (VENTURA, 1995).

Somadas às inúmeras políticas públicas que incidiram na cidade carioca, e em especial nas favelas, destaca-se a criação da Secretaria Municipal de Habitação no Rio de Janeiro, em 1994, que planejou e executou o Programa Favela-Bairro, que tinha como meta integrar a favela à cidade com a implantação de infraestrutura urbana, serviços, equipamentos públicos, políticas sociais e melhorias na urbanização. Esse programa foi instituído na primeira gestão do prefeito Cesar Maia, "obteve grande repercussão, e influenciou uma série de programas similares em outras cidades. (YUHASZ, 2013, p. 44)".

Há de se destacar também, em 2008, a atual política de segurança do Rio de Janeiro, a já falida Unidade de Polícia Pacificadora(UPP), surge implantada pelo governo estadual, adotada como "política de pacificação para diferenciar o que se praticava como política de segurança pública habitual em relação ao restante da cidade" (RODRIGUES, 2014, p. 22). O objetivo principal das UPP seria, de acordo com o governo do estado, reestabelecer a ordem e a segurança em territórios centrais marginalizados, mas foram implantadas naqueles que exercem grande influência na cidade, seja ela turística ou econômica.

Dessa forma, o presente trabalho tem o propósito de demonstrar como a ação do Estado, enquanto formulador e implementador das políticas públicas na cidade do Rio de Janeiro e promotor do planejamento urbano propiciaram o surgimento e a expansão das favelas cariocas e de que maneira essas políticas convergiram na tentativa de formatação de um processo de segregação e controle das favelas na cidade. Para tanto, possui enquanto objetivos realizar uma revisão bibliográfica acerca das principais políticas públicas no pelo Estado na cidade do Rio de Janeiro que propiciaram o surgimento e a expansão das favelas cariocas, e analisar de que maneira as políticas públicas que incidiram na cidade e principalmente nas favelas foram utilizadas enquanto mecanismo de segregação e controle da população mais pobre, discutindo o real papel das UPP nas favelas enquanto política pública de segurança para o ordenamento social, dando destaque às redes ${ }^{1}$ de resistências organizadas nas favelas. 


\section{O Planejamento urbano hegemônico na cidade do Rio de Janeiro e as políticas segregacionistas nas favelas cariocas}

A cidade como campo de transformações políticas e intervenções sociais surge no Brasil enquanto objeto de estudo por volta de 1902, quando a questão da saúde pública brasileira toma proporções. Surtos de doenças como a varíola e a febre-amarela, deram suporte a um discurso cientificista e higienista que deram base às intervenções urbanas durante a gestão de Pereira Passos no município do Rio de Janeiro (1902-1906).

Pela perspectiva habitacional tem-se a política do "bota abaixo" que promoveu a remoção da população dos cortiços, becos e vielas para as áreas afastadas do centro urbano da cidade do Rio de Janeiro, sendo justificada por médicos e especialistas que visavam garantir maior circulação de ar no centro, em detrimento do vínculo que os habitantes mais pobres tinham com aqueles espaços. Sobre essa perspectiva Pereira e Carvalho (2008) vão identificar que "a ciência se tornou a forma de racionalidade hegemônica" (PEREIRA; CARVALHO, 2008, p. 47).

A reforma do prefeito Pereira Passos tinha a intenção implícita de promover o afastamento da população mais pobre do centro da cidade. Essa ação deixou claro o grande atraso, para os planos de elitização da cidade, que era ter a pobreza junto ao centro carioca (AMORIM; RIBEIRO; SEGHETO JÚNIOR, 2008).

Uma reportagem do Jornal do Brasil (1903) descreve a demolição da cidade colonial como uma forma de tornar a cidade do Rio de Janeiro uma capital civilizada. Aos pobres, segundo a mesma reportagem, só restava como alternativa a ocupação do Morro da Favela, tendo este, despontado como a primeira favela carioca, fruto das políticas de "embelezamento" da cidade e da articulação da população pobre em torno do direito a moradia. Sobre esse discurso e ações de imposição de um modelo europeu de "civilização", Santos (2007) analisa que:

[...] o pensamento abissal moderno, que deste lado da linha era chamado a regular as relações entre cidadãos e entre estes e o Estado, é agora chamado, nos domínios sociais sujeitos a uma maior pressão por parte da lógica da apropriação/violência, a lidar com os cidadãos como se fossem não-cidadãos e com os não-cidadãos como se fossem perigosos selvagens coloniais. (SANTOS, 2007, p. 83)

A partir da análise do pensamento abissal de Santos é possível traçar um paralelo com as intervenções do Estado no Rio de Janeiro. A exclusão dos pobres do centro da cidade para sua modernização e europeização, tal qual uma linha abissal, criou uma divisão simbólica, mas bastante rígida, que polarizou a sociedade carioca: de um lado da linha os ricos, do outro lado, os pobres.
Assim, foi consolidada a dinâmica de construção da "cidade partida". Essa lógica fez/faz ainda hoje com que:

[...] as famílias excluídas do mercado imobiliário e das políticas compensatórias da Habitação de Interesse Social procurem nos interstícios da urbanização formal locais de escasso valor fundiário, em decorrência da localização: distante, em encostas ou áreas inundáveis. As casas são construídas pela própria família, parentes e amigos, que utilizam como materiais de construção elementos reciclados ou de baixa qualidade. (MORA, 2010, p. 3)

No Rio de Janeiro, em virtude da política higienista e de embelezamento de Vargas, em 1937 fora instituído o "Código de Obras", cujo objetivo principal seria coibir o surgimento de novas favelas, propondose a administrar e controlar o crescimento das que já existiam. Vale frisar que o Código de Obras pode ser considerado a primeira política formal do governo diretamente voltada às favelas no Rio de Janeiro, preocupando-se em respaldar toda e qualquer ação que propusesse uma intervenção neste aglomerado social (CORREIA, 2006).

As seguidas iniciativas governamentais de remover as favelas em 1960 e 1970 enfrentaram, contudo, grande reação social, e resistência de moradores, estudantes e intelectuais da época, que em "redes" lutavam por um processo de urbanização democrático no espaço urbano da cidade do Rio de Janeiro, e objetivavam a não expulsão da população mais pobre das áreas centrais e a manutenção do direito a moradia nas favelas.

Sob a perspectiva de resistência, a Federação das Associações de Favelas do Estado da Guanabara (Fafeg) foi criada, com foco na inspiração do político esquerdista Luis Carlos Prestes, sendo um importante órgão para reprimir a política de remoção das favelas na época da ditadura militar, mesmo sofrendo repressão política. Nesse sentido, ao final da década de 1970, essas inúmeras reações promoveram o aumento dos custos das remoções, pois a resistência articulada por essa população encarecia os custos do processo, fato que resultou no abandono do projeto, conforme apontam Barreira e Botelho (2008).

É possível refletir, como nos sugere Ferreira Junior (2004), que o papel do planejamento ganha um desígnio maior em 1970, adentrando pelos anos 1980, quando a característica intervencionista e reguladora assumida pelo Estado, assume a finalidade de manter a cidade sob o julgo das necessidades e dos ideais de uma política hegemônica. Mesmo assim, os casebres e barracos, de todo o tipo de material reaproveitado, espalharam-se rapidamente nessas décadas e, as favelas, continuavam a crescer em áreas periféricas e centrais, gerando, no entanto, incômodo a população das classes média e alta da cidade.

Dentro desse contexto de crescimento das 
favelas, mas de incômodo das classes mais favorecidas da pirâmide social, ainda nos anos 1970, sob a gerência dos militares, nota-se um movimento de reconhecimento da favela enquanto espaço de moradia. Entretanto, esse movimento possuía objetivos claros: conter a mobilização dos favelados e suas articulações políticas nesses espaços, visando enfraquecer os movimentos contrários ao processo urbanizador do Rio de Janeiro (BARREIRA; BOTELHO, 2008). Isso porque, o reconhecimento das favelas enquanto espaço de moradia serviu apenas como válvula de escape para a solução dos problemas ligados a urbanização do município, pois, a favela passava a ser a própria solução, na medida em que abrigava a população excluída às margens da cidade.

Entre os anos de 1983 e 1987, o governo Brizola, no Rio de Janeiro, partindo dessa premissa de favela como área legítima de habitação e local característico das classes pobres, de baixos salários e trabalhadores informais promove uma espécie de upgrade das favelas, através da implementação de saneamento, pavimentação e da legalização do espaço. (BARREIRA; BOTELHO, 2008)

Essa opção pela urbanização das favelas cariocas é resultado de uma nova visão de Estado dando a entender uma possível democratização do sistema político, iniciando a partir da década de 1980 a implementação de serviços básicos e equipamentos sociais para a população. Vai ao encontro dessas mudanças o Programa Favela-Bairro, inaugurado em 1994, promovido no governo Cesar Maia e os financiamentos do Banco Interamericano e Desenvolvimento (BID) obtidos para financiar políticas urbanizadoras na cidade (BARREIRA; BOTELHO, 2008).

Em 1996 é eleito como prefeito Luiz Paulo Conde, que já havia ocupado o cargo de secretário de urbanismo do prefeito César Maia, com a finalidade de dar continuidade às políticas implementadas. No ano 2000, César Maia é novamente eleito e reeleito em 2004, consolidando, em longo prazo, o programa Favela-Bairro.

Outras das iniciativas, mais recentes, de (re) construção das favelas como espaço de moradia foi o Programa de Aceleração do Crescimento (PAC) que vem atuando sob sua vertente de promoção de infraestrutura nas favelas, iniciado em 2007. Nas favelas e para a população mais carente da cidade incidiram ainda, programas como: Morar Carioca (do município implantado em 2010 com a finalidade de urbanizar e integrar socialmente, as favelas cariocas até 2020), e o Minha Casa Minha Vida (governo federal, sob o discurso de promover dignidade e cidadania por meio da oferta de habitação). Esses programas, no entanto, sofrem duras críticas por não proporcionarem grandes mudanças na vida da população nas favelas, no caso do PAC, por exemplo, as obras de infraestrutura acabam por não darem conta de resolver os principais problemas enfrentados nas favelas como a falta de mobilidade e a logística de recolhimento do lixo. O Morar Carioca sofreu críticas pela morosidade das obras e por entregar casas em estado precário. E o programa Minha Casa Minha Vida não tem conseguido atender a população mais pobre próximo ao seu local de moradia original, sendo queixa frequente a distância do centro em que as unidades habitacionais são construídas, em locais geralmente sem infraestrutura e desvalorizados.

\section{Rio: cidade mercadoria, favela e UPP}

De acordo com Mora (2010) o processo de acumulação do capital no sistema deeconomia capitalista, é o responsável pelo caos urbano instaurado nas cidades, manifestando, segundo sua lógica hegemônica, a segregação espacial pela favelização e pelo déficit qualitativo e quantitativo de habitações, principalmente nas grandes cidades. Essa lógica de produção informal do habitat é um componente bastante representativo do crescimento das cidades latino-americanas que produzem um déficit permanente em virtude da subordinação da política urbana ao interesse do capital. O que pode ser confirmado a partir do histórico de políticas urbanas implementadas pelo Estado na cidade do Rio de Janeiro, destacadas anteriormente.

Sob a égide das políticas segregacionistas e da construção social sob a lógica de acumulação do capital e da exclusão consciente, nas décadas de 1970 e 1980, intensificou-se no Rio de Janeiro, o tráfico de drogas, que acabou por encontrar abrigo territorial nas favelas. O narcotráfico instituiu, nesse período, uma guerra territorial interna (entre as próprias facções rivais pelo domínio do território) e externa (com a polícia), o que resultou no aumento dos índices de violência no município (JOVCHELOVITCH; PRIEGOHERNÁNDEZ, 2013).

Em paralelo as políticas segregacionistas, precárias e de pouco efeito transformador nas favelas, o tráfico de drogas se instalou, se tornando um relevante organizador da sociedade local, passando a permitir, comandar e interditar a vida e os afazeres da população. O narcotráfico passa a exercer papel institucional, se fazendo predominante em virtude da deficiência e/ou do desinteresse do Estado em ocupar, com qualidade, equipamentos e serviços, esses territórios.

A atuação do narcotráfico foi combatida por um Estado repressor, "com um rígido controle das populações pobres, em especial os negros" (RIBEIRO; DIAS; CARVALHO, 2008, p.7). O Estado baseavase em uma política de segurança punitiva onde por meio das chamadas megaoperações e dos autos de resistências transformavam ações de segurança pública em atos de combate e extermínio da população mais 
pobre (RIBEIRO; DIAS; CARVALHO, 2008).

As ações de segurança pública implementadas ao longo dos governos que se seguiram no Rio de Janeiro estavam baseadas na concepção de uma espécie de guerra contra o crime, "no confronto armado e na criminalização da pobreza" (RIBEIRO; DIAS; CARVALHO, 2008, p. 8). A premiação faroeste ${ }^{2}$, a Operação Rio Seguro ${ }^{3}$ e as megaoperações policiais, foram exemplos das políticas de enfrentamento reproduzidas pelo Estado que objetivaram o confronto armado e a morte de criminosos.

Essas ações repercutiram de diferentes formas nas várias camadas sociais do Rio de Janeiro: por um lado, aumentava-se a sensação de segurança das classes média e alta nas áreas mais nobres da cidade, por outro, os mais pobres sofriam com a perseguição policial e os confrontos nas comunidades, fatos que agravavam a falta de confiança dessa população na polícia e que disseminavam o medo nessas localidades.

Em meio a esse cenário de "guerra contra o crime" ganhou destaque, em 2007, sob o comando do Secretário de Segurança do Rio de Janeiro José Mariano Beltrame, no governo de Sérgio Cabral a UPP, implementada, de fato, em 2008, sendo a primeira das 38 que se seguiram, no Santa Marta.

Com o advento da UPP, o governo do Estado compartilhou com a sociedade o projeto de polícia de proximidade, a ideia de distanciamento das iniciativas e modelos de política de ordenamento territorial excludente e de uma política de segurança baseada em uma polícia truculenta e agressiva. As UPP, deveriam projetar uma nova perspectiva para a vida da população das favelas e do entorno, propiciando uma reorientação dos fluxos da cidade para além da fragmentação de seu território.

Para além da conduta policial truculenta, nos últimos anos, as favelas pacificadas se viram novamente imersas no cotidiano de troca de tiros e tráfico armado. Dois dos principais veículos de comunicação da cidade trouxeram em suas manchetes essa violência: "PMs do Rio são condenados pela morte do menino Juan Moraes" (PORTAL G1, 2013); "Tráfico mostra seu poderio bélico em áreas pacificadas" (PORTAL O DIA, 2014);“Mortes em favelas com UPP aumentam em 55,3\%" (PORTAL O DIA, 2015); "Homicídio no Dona Marta é o $1^{\text {a }}$ desde 2008, quando UPP foi criada" (PORTAL G1, 2016);

Pesquisadores apontam ainda para o processo de "gentrificação" em inúmeras favelas "pacificadas", justamente por terem passado por um processo de valorização do espaço, ocasionado pela política de segurança, pela abertura ao mercado e pelo advento do turismo em muitos desses territórios, o que ocasionou o aumento nos preços dos imóveis e serviços, impactando a vida dos moradores que passaram a ter que lidar com uma segregação inusitada que os empurrou para fora, também, desses territórios.
Santos (2003) remete a perversidade do sistema capitalista ao comportamento competitivo inerente as ações hegemônicas do processo de globalização. "Todas essas mazelas são direta ou indiretamente imputáveis ao presente processo de globalização" (SANTOS, 2003, p. 10). As UPP e o projeto de pacificação, nesse contexto, emergem aqui como mais um mecanismo, mais uma força dentro de uma instituição historicamente truculenta e de orientação segregacionista, a polícia militfar, e de um Estado orientado para suprir as necessidades do capital, para reproduzir ações hegemônicas que vão de encontro à dinâmica de apropriação global dos territórios, das coisas e das pessoas.

Não à toa, no mundo contemporâneo, o conceito de "pacificação" é utilizado para fazer referência à intervenção do Estado nas favelas, áreas que anteriormente não estavam sob o seu domínio. A palavra "pacificação" trás de volta a ideia de missão civilizatória de uma elite dirigente hegemônica e dos poderes públicos, tal qual no período colonial. O "outro" contemporâneo, imaginado como tão diferente e externo aos usos e costumes hegemônicos globais deve ser apropriado, controlado, pacificado e disciplinado.

As UPP trouxeram, na verdade, em detrimento de uma política pública de rompimento de estigmas e quebra de barreiras, uma política pública de ordenamento. O que se denomina como ordem, de acordo com Ferraz (2012), é o resultado da luta de classes expressa nos espaços da "Cidade Maravilhosa" pelas desigualdades em todos os níveis. Essa ordem almejada é o resultado de ações impositivas de enquadramento, controle das pessoas que estão fora da ordem. É a ordem do capitalismo global, do poder hegemônico e dominante que deseja exterminar com as resistências e redes formadas e fortalecidas nas favelas.

\section{Formação de redes e resistências nas favelas cariocas}

No ano de $2010,06 \%$ da população brasileira $(11,4$ milhões de pessoas) residia em favelas, sendo a região Sudeste, com 5,5 milhões de indivíduos, seu principal expoente (CAVALLIERI; VIAL, 2012). Nessa região, o Rio de Janeiro e São Paulo são os maiores destaques. Em específico à cidade carioca, estima-se que 1.393.314 pessoas estão alocadas em 763 favelas. Ou seja, 22,03\% de sua população vivencia particularidades, positivas e/ ou negativas, pertinentes as esferas sociais, culturais, políticas, ambientais, espaciais e econômicas desses núcleos urbanos (GALDO, 2011).

Tais localidades são vinculadas, corriqueira e pejorativamente, a um ideal sócio identitário que transparece insegurança, caos e instabilidade, graças a algumas das principais mazelas observadas nos grandes centros urbanos: criminalidade, tráfico de drogas e a 
violência (ZALUAR, 2009).

Em vista da ordem do capitalismo global que tem por objetivo pautar o desenvolvimento das cidades sob as arestas do poder hegemônico e dominante, mesmo em detrimento dos mais pobres, a sociedade menos favorecida nas favelas buscou se articular, desde sua gênese, a fim de resistir às mudanças impostas e a tutela do poder público. A essa articulação de indivíduos dá-se o nome de rede social.

O entendimento de rede, no entanto, não pode ser confundido com a mera formação de grupos. Isso porque, uma rede deve possuir, para além da formação constituída por um conjunto de pessoas, a capacidade de articulação e rearticulação permanente (ENNE, 2004). Dessa maneira, podemos entender por redes a conceituação criada por Barnes, e citada por Enne (2004, p. 264), como aquela "[...] pensada socialmente, composta por indivíduos que irão se articular a partir de interações, e não por composições egocêntricas".

As formações de redes sociais de resistência constituíram, e ainda constituem a realidade das favelas do Rio de Janeiro. Historicamente, as construções de moradias que originariam as favelas foram, em um primeiro momento, fruto do descaso do poder público com a população em nível econômico inferior, que teve como opção se instalar nos morros dos arredores do centro da cidade. Sendo, posteriormente, fortalecidas por movimentos sociais de resistência, que se articulavam em rede para garantir o direito a moradia e a permanência nas favelas cariocas.

A criação de redes de resistências sociais pelas populações das favelas foi crucial para sua consolidação enquanto povo. Como exemplo, pode-se citar a resistência dos moradores da comunidade do Vidigal $^{5}$ durante as décadas de 1960 e 1970, quando foram alvos da tentativa de remoção, tanto pelo poder público, como por pressão de iniciativas privadas que chegaram a construir um hotel de luxo da rede Sheraton na tentativa de privatizar tanto a praia do Vidigal, quanto uma das mais belas vistas do Rio de Janeiro. Apenas uma, das várias favelas onde incidiram políticas e ações que objetivaram remover, cercear e tutelar moradores, territórios e suas articulações. Mais recentemente, em 2013, moradores do Morro da Providência, localizado no centro do Rio de Janeiro, sofreram constantes assédios de funcionários da Secretária Municipal de Habitação $(\mathrm{SMH})$ para que deixassem suas casas, mediante a promessa de pagamentos de indenizações ou moradias em outros locais. Essa tentativa de remoção foi fruto do Programa Morar Carioca, iniciado em 2010 pela Prefeitura do Rio de Janeiro, objetivando intervenções urbanísticas para a construção de um teleférico conectando a estação de trem Central do Brasil ao topo da favela. E, muito embora tenha havido ampla formação de redes de resistências de moradores, dezenas de famílias foram removidas para a concretização da obra.
Os exemplos de resistência dos moradores demonstram um movimento de caráter contra hegemônico que vão de encontro os interesses de uma sociedade capitalista global. De acordo com Santos (2007), os movimentos contra globais devem existir como uma espécie de freio a um capitalismo perverso, podendo estes alcançar o sucesso, na medida em que se articulam e enfrentam as situações mais adversas impostas pelos mecanismos do capitalismo global.

Em ambos os casos, Vidigal e Providência (e inúmeros outros ocorridos cotidianamente nas favelas cariocas), o objetivo real do Estado e das elites mantenedoras do controle do mercado, sempre veio mascarado sob a ilusão da implementação de políticas públicas setoriais e ações para melhorias da qualidade de vida nas favelas, o que em tese, justificaria a truculência e o assédio cometido nesses territórios. Até mesmo o projeto de pacificação por meio das UPP, incididas em 37 favelas na cidade carioca, emergiu por meio de um discurso de polícia de proximidade, buscando cooptar a população favelada sob o seu próprio aval, quando, na verdade, a intenção nunca foi integrar as favelas, e nem mesmo a segurança local, sendo o propósito final do projeto a produção da cidade para a captação e realização dos megaeventos mundiais ocorridos em 2014 e 2016.

Os objetivos das mais diversas tentativas de apropriação dos territórios de favela, sempre foram a construção de espaços vendáveis. No caso do Vidigal, dada a sua localização geográfica, houve (e há) grande especulação imobiliária e, portanto, há interesse do mercado em adquirir esses territórios. Já na Providência, a intenção foi produzir um legado Olímpico, por meio da possibilidade de se realizar turismo nesse espaço que seria aliado à Zona Portuária "revitalizada", um negócio turístico altamente lucrativo, inclusive com a construção do Museu do Amanhã.

\section{Considerações Finais}

Como alternativa a realidade contemporânea aos reflexos do acelerado processo de urbanização, há no planejamento urbano um refúgio no qual o poder público pode se posicionar enquanto agente responsável pela solução dos problemas sociais da cidade.

O planejamento urbano e a gestão do espaço das cidades devem ser compreendidos, de maneira holística, considerando as suas dimensões histórica, política e social, como instrumentos capazes de reconstituir, por meio de políticas públicas, a ideia de espaço integral e contínuo, mas que se diferencia da perspectiva global hegemônica de apropriação, entendendo, portanto a cidade em toda a sua diversidade e múltiplas facetas.

Diante desse desafio de entender as transformações das cidades para alcançar intervenções relevantes, 
democráticas e qualificadas é imprescindível considerar a efetiva participação popular tanto na validação, quanto na construção das políticas públicas para o desenvolvimento territorial.

Afinal, a cidade não é apenas o local de produção e venda. É espaço de compreensão das práticas sociais. As favelas cariocas, nesse sentido, são exemplos de territórios que sofrem com as remoções e com a gentrificação, bem como com a tutela do território seja por meio da urbanização, da presença ostensiva da polícia, ou de políticas públicas segregacionistas.

A participação política do povo e a sua organização em redes de movimentos sociais possui um papel fundamental para o fortalecimento da relação entre sociedade e Estado. Ao formalizar redes de resistências e participar dos processos de elaboração e decisão das políticas, a sociedade organizada pode buscar enfrentar a natureza do sistema capitalista de reprodução da desigualdade para continuar operando.

A necessidade da organização da sociedade, e de contra movimentos globais, evidencia a importância de se construir um pensamento pós-abissal como uma promessa real que pode configurar o que se entende como globalização contra hegemônica, uma forma de lutar contra a exclusão social, econômica, política e cultural ocasionada pelo capitalismo global.

Sem os contra movimentos sociais, com o Estado como o único detentor da força ou do poder de intervir no espaço urbano, haverá apenas a reprodução da ideologia dominante ou tão somente a manutenção de suas estruturas, como observado ao longo do século XX até os dias atuais com as UPP.

Destarte, não é estranho concluir, após debruçar sobre o debate e sobre todas as informações mencionadas, que as UPP, acabaram por ajudar a reproduzir as mesmas características segregacionistas e antidemocráticas das políticas públicas e ações governamentais outrora implementadas na cidade e nas favelas cariocas. Em detrimento da democratização do espaço e da reorganização da cidade em torno da quebra de estigmas, reproduzem ações excludentes e agressivas de um modelo dominador hegemônico para com a população mais pobre e reforçam, nas favelas, $\mathrm{o}$ sanitarismo do século XX, perseguindo a consolidação de uma cidade global à face do modelo de sistema capitalista e da globalização perversa que Milton Santos abordou.

A modernização (ou a falsa modernização) e a urbanização influenciam na intensificação da pobreza e segregam as classes sociais. Assim, a estrutura da pirâmide que representar a sociedade terá sempre como base aqueles menos favorecidos dentro do sistema, independente do crescimento urbano e até mesmo do desenvolvimento urbano.

Está posto que por meio de várias políticas públicas e ações, historicamente, o Estado propôs, no
Rio de Janeiro, uma política hegemônica de produção da cidade aos moldes do capital global, buscando controlar, tutelar e até certo ponto, por meio da falsa ideia de integração de políticas de melhoramento das favelas e das UPP, cooptar a população mais pobre, em prol de seus interesses dominantes de desenvolvimento econômico da cidade. Ademais, ainda que vigente, está claro que as UPP implantadas, em especial na cidade do Rio de Janeiro, não deram certo, podendo-se falar na falência do projeto de pacificação cujos objetivos reais se configuraram muito mais em torno da produção de uma cidade vendável do que do bem-estar dos mais pobres.

\section{Nota}

1. Adotar-se-á como conceito de redes os fluxos de bens e informações, a partir de práticas de interação social, a posição de Barnes (1964) que entende como sendo a composição de indivíduos que irão se articular a partir de interações e não por composições egocêntricas. Ler mais em: <https://www. revistas.ufg.br/ci/article/viewFile/24452/15165?journal=ci>

2. Operação implementada no em 2003 sob o comando do então secretário de segurança Josias Quintal, que buscava o confronto direto e armado com criminosos.

3. Incursões de grupos policiais ocorridas nas favelas, a partir de 2007 no governo de Sérgio Cabral, sob o comando do Secretário de Segurança José Mariano Beltrame. As megaoperações eram justificadas como ações pacificadoras e de combate à força armada do tráfico.

4. O conceito de gentrificação foi cunhado em 1964 com enfoque no mercado imobiliário e na substituição da população mais pobre pela nova classe média. Smith (2006), aponta que a gentrificação envolve não apenas mudança social, mas também uma mudança física nas habitações em determinado território em um processo combinado a "higienização social", acarretando o aumento do custo de vida para a população e em especulação imobiliária.

5. Localizada entre os bairros do Leblon e São Conrado, na nobre Zona Sul do Rio de Janeiro.

\section{Referências}

AMORIM, C. C.; RIBEIRO, S. S; SEGHETO JUNIOR, I. . Turismo em favelas: um estudo de caso na favela da rocinha. In: Estação Científica, v. 06, p. 1-21, 2008.

BARREIRA, M. R. A.; BOTELHO, L. B. Crise urbana e favelização no Rio de Janeiro:para uma crítica da "questão urbana" contemporânea. In: III Simpósio Lutas Sociais na América Latina, Londrina, 2008. Disponível em: www.uel.br/grupopesquisa/gepal/terceirosimposio. Acesso em: 14 jun. 2012 .

CAVALLIERI, F.; VIAL, A. Favelas na cidade do Rio de Janeiro: o quadro populacional com base no Censo 2010. Coleção Estudos Cariocas, $n^{\circ}$ 20120501, pp. 01-18, 2012

CAMPOS, A. O. Do quilombo à favela: A produção do espaço criminalizado no Rio de Janeiro. 3. ed. Rio de Janeiro: Bertrand Brasil, 2005. v. 500. 210

CORREIA, Fernanda. Breve histórico da questão habitacional na cidade do Rio de Janeiro. Revista de Ciências Políticas. Portugal, n.31. 2006. Disponível em: http://www.achegas.net/numero/31/fernanda _correa_31. pdf. Acesso em: 2 maio 2012.

CUNHA, N.; MELLO, M. A. Novos conflitos na cidade: A UPP e o processo de urbanização na favela. Dilemas: Revista de Estudo de Conflito e Controle Social, Vol.4, n³, pp. 371-401, 2011.

ENNE, Ana Lúcia S. Conceito de rede e as sociedades contemporâneas Comunicação e informação, v. 7, n.2,: p. 264-273- Jul/Dez, 2004. 
FERREIRA JUNIOR, J. C. Limites e Potencialidades do Planejamento Urbano: uma discussão sobre os pilares e aspectos recentes da organização espacial das cidades brasileiras. In: Estudos Geográficos. Rio Claro, 2004. n.1. v.2. p. $15-28$

FUNDAÇÃO GETÚLIO VARGAS - FGV. Pesquisa traça panorama do turismo em favelas do Rio de Janeiro (2013). Disponível em: http:// www.editora.fgv.br/blog/atualidades/panorama-do-turismo-nas-favelaspacificadas-do-rio-de-janeiro/. Acesso em: 06 mar. 2014.

GALDO, R. Rio é a cidade com a maior população em favelas do Brasil. O Globo, Rio de Janeiro, 21.dez.2011. Disponível em: http:/oglobo.globo.com/ brasil/rio-a-cidade-com-maior-populacao-em-favelas-do-brasil-3489272. Acesso em: 01 jul. 2015.

JOVCHELOVITCH， S.; PRIEGO-HERNANDEZ， J. Sociabilidades subterrâneas: identidade, cultura e resistência em favelas do Rio de Janeiro. Brasília: UNESCO, 2013. Disponível em: http://unesdoc.unesco.org/ images/0022/002238/223831 por.pdf. Acesso em: 02 maio 2014.

LANCA, V. S; MAIA, L. M; SANTANA, M. P. L. Planejamento urbano e turismo: uma análise sobre a Favela da Rocinha (RJ). Caderno Virtual de Turismo. Rio de Janeiro, v. 15 n.1. p.20-34, abr. 2015.

MORA, L. de. Produção Social do Habitat: Estratégia dos excluídos para a conquista do direito à cidade e à moradia. In: Novos Padrões de Acumulação Urbana na Produção do Habitat. Olhares Cruzados Brasil - França. Editora Universitária, UFPE, 2010.

NOGUEIRA, M. A. Sociedade Civil, entre o Político-Estatal e o Universo Gerencial. RBCS. v. 18 n. 52, 2003.

PEREIRA, Eduardo Tadeu. Boaventura de Sousa Santos e a Sociedade Civil em tempos de globalização. Revista Filos, Aurora, Curitiba, v.20, Jan/jun, 2008.

PEREIRA, M. A; CARVALHO, E. Boaventura de Sousa Santos: Por uma nova gramática do político e do social. Lua Nova, São Paulo, 73: 45-58, 2008 .

PORTAL G1. PMs do Rio são condenados pela morte do menino Juan Moraes. Rio de janeiro, 2013. Disponível em: http://g1.globo.com/rio-dejaneiro/noticia/2013/09/pms-do-rio-sao-condenados-pela-morte-do-meninojuan-moraes.html. Acesso em: 08 mai. 2016.

. Homicídio no Dona Marta é o $1^{\text {a }}$ desde 2008, quando UPP foi criada. Rio de Janeiro, 2016. Disponível em: http://g1.globo.com/rio-de-janeiro/ noticia/2016/03/homicidio-no-dona-marta-e-o-1-desde-2008-quando-uppfoi-criada.html. Acesso em: 08 mai. 2016.

PORTAL O DIA.“Tráfico mostra seu poderio bélico em áreas pacificadas". Rio de Janeiro, 2014. Disponível em: http://odia.ig.com.br/noticia/rio-dejaneiro/2014-03-09/trafico-mostra-seu-poderio-belico-em-areas-pacificadas. html. Acesso em: 08 mai. 2016.

Mortes em favelas com UPP aumentam em 55,3\%. Rio de Janeiro, 2015. Disponível em: http://odia.ig.com.br/noticia/rio-de-janeiro/2015-1116/mortes-em-favelas-com-upp-aumentam-em-553.html. Acesso em: 08 mai. 2016.

PORTAL UPP RJ. O que é? Disponível em: http://www.upprj.com/index. php/o_que_e_upp. Acesso em: 08 mai. 2016.

RAFFESTIN, C. Por uma Geografia do Poder. São Paulo: Ática, 1993.

RIBEIRO, Camila; DIAS, Rafael; CARVALHO, Sandra. Discursos e práticas na construção de uma política de segurança: O caso do governo Sérgio Cabral Filho (2007-2008). Segurança, tráfico e milícia no Rio de Janeiro / organização, Justiça Global- Rio de Janeiro: Fundação Heinrich Böll, 2008.

RIOONWATCH - Programa Morar Carioca. Disponível em: http:// rioonwatch.org.br/?p=12410. Acesso em: 10/05/2015.

RODRIGUES, M.: Tudo junto e misturado: o almanaque da favela: turismo no Santa Marta. 1 ed. Rio de Janeiro: Mar de Ideias, 2014.

SANTOS, Boaventura de Sousa. Para além do pensamento abissal. Novos Estudos, v.79, p.71-94, 2007.

SANTOS, Milton. Por uma outra globalização: do pensamento único à consciência universal. 10. ed. Rio de Janeiro: Record, 2003.
. A Pobreza Urbana. 3 ed. São Paulo: Edusp. 1996. Cap. 2 e 3.

SAVIANI FILHO, H. A era Vargas desenvolvimentismo economia e sociedade. In: Revista economia e sociedade, v. 22 n.3, 2013.

SMITH, Neil. A gentrificação generalizada. In: BIDOU-ZACHARIASEN, Catherine. Introdução. De volta à cidade: dos processos de gentrificação às políticas de "revitalização" dos centros urbanos. São Paulo: Annablume, 2006, p. $59-87$

VALLADARES, Licia. A gênese da favela carioca. A produção anterior as ciências sociais. Revista Brasileira de Ciências Sociais. Vol.15 nº44. 2000 Disponível em: < http://www.scielo.br/pdf/rbcsoc/v15n44/4145.pdf>. Acesso em: 15 out. 2011.

VENTURA, Zuenir. Cidade Partida. Rio de Janeiro: Companhia das Letras, 1995.

VILLAÇA, Flávio. Espaço Intra-Urbano no Brasil. São Paulo, Studio Nobel, 2001.

ZALUAR, A. Pesquisando no perigo: etnografias voluntárias e não acidentais. Revista Mana - Estudos de Antropologia Social, v.15, n02, pp. $557-584,2009$

ZALUAR, A.; ALVITO, Marcos. Um século de Favela. 5a edição - Rio de Janeiro: Editora FGV, 2006.

ZALUAR, A.; NORONHA, J. C. \& ALBUQUERQUE, C. Violência: Pobreza ou Fraquesa Institucional? Cad. Saúde Públ., Rio de Janeiro, 1994.

YUHASZ. D. As Propostas de Integração das Favelas Cariocas e as Disputas pelos Benefícios Gerados: O Valor da Terra e o Saldo da Dívida Social. Dissertação de Mestrado. Escola de Arquitetura e Urbanismo. Universidade Federal Fluminense, Rio de Janeiro, 2013. 